\title{
Functional characterization of the complement receptor type 1 and its circulating ligands in patients with schizophrenia
}

\author{
Arsen Arakelyan', Roksana Zakharyan 1,2, Aren Khoyetsyan', David Poghosyan', Rouben Aroutiounian 1,3, \\ Frantisek Mrazek2, Martin Petrek ${ }^{2}$ and Anna Boyajyan ${ }^{1 *}$
}

\begin{abstract}
Background: Whereas the complement system alterations contribute to schizophrenia, complement receptors and regulators are little studied. We investigated complement receptor type 1 (CR1) expression on blood cells, the levels of circulating immune complexes (CIC) containing ligands of $\mathrm{CR} 1, \mathrm{Clq}$ complement protein and fragments of C3 complement protein (C1q-CIC, C3d-CIC), and CR1 C5507G functional polymorphism in schizophrenia patients and controls.
\end{abstract}

Results: We found an increased C1q-ClC level and CR1 expression on blood cells, elevated number of CR1 positive erythrocytes and reduced number of CR1 positive lymphocytes and monocytes in patients compared to controls. No difference in the levels of C3d-CIC between groups was observed. Higher CR1 expression on erythrocytes in CC genotype versus CG+GG for both groups was detected, whereas no difference was observed for other cell populations. Our results indicated that schizophrenia is associated with the increased CR1 expression and C1q-CIC level.

Conclusions: Our study for the first time indicated that schizophrenia is associated with the increased CR1 expression and $\mathrm{Clq}-\mathrm{ClC}$ level. Further studies in other ethnic groups are needed to replicate these findings.

\section{Background}

Complement receptor type 1 (CR1; CD35; C3b/C4b receptor) is a multifunctional receptor, which is expressed in the majority of peripheral blood cells [1-4], with high affinity to complement components $\mathrm{C} 1 \mathrm{q}, \mathrm{C} 3$, C4 [5-8] and mannose-binding lectin [9]. Binding of CR1 to opsonic fragments of the complement $\mathrm{C} 3$ and $\mathrm{C} 4$ components (C3b, C4b, iC3b, and C3dg) and to the complement component $\mathrm{C} 1 \mathrm{q}$ attached to immune complexes (IC), foreign or damaged host cells serves to mediate clearance of IC (on erythrocytes (E)) $[4,10]$ and phagocytosis of complement-coated particles (on leukocytes) $[3,11,12]$. In addition, interaction of CR1 with its ligands plays further roles in regulation of lymphocyte (L) activity by promoting secretion of interleukin (IL)- $1 \alpha$, IL-1 $1 \beta$, and prostaglandins [13]. Furthermore, CR1 plays a role in

\footnotetext{
* Correspondence: aboyajyan@sci.am

'Institute of Molecular Biology, National Academy of Sciences of the

Republic of Armenia, 7 Hasratyan St., 0014, Yerevan, Armenia

Full list of author information is available at the end of the article
}

antigen presentation to B cells [12]. In addition to membrane-bound CR1, leukocytes also release soluble form of CR1, which is a potent inhibitor of both the classical and the alternative pathways of complement activation by exhibiting decay-accelerating activity for both C3 and C5 convertases, as well as cofactor activity for factor Imediated cleavage of C3b and C4b $[10,13,14]$.

A number of studies suggest the involvement of alterations in the immune response, including autoimmune and inflammatory mechanisms, in the aetiopathogenesis of schizophrenia [15-17]. Alterations in functional activities of classical, alternative and lectin pathways of complement, a major mediator of the immune response, as well as changes in blood levels and expression profiles of its $\mathrm{C} 1 \mathrm{q}, \mathrm{C} 3$, and $\mathrm{C} 4$ components have been detected in schizophrenia-affected subjects [18-22]. However, little is known about receptors and regulators of the complement system in schizophrenia. Here CR1 represents a special interest, accounting for a positive genome-wide linkage of schizophrenia with the

\section{C) Biomed Central}


CR1 gene encoding locus (1q32) [23]. A common CR1 C5507G single nucleotide polymorphism (SNP) in exon 33 has been shown to be associated with some diseases characterized by altered inflammatory response [24,25], and changes in CR1 expression have been shown in patients with a variety of inflammatory and autoimmune diseases [14,26-28].

In the present study we investigated the expression of CR1 on E and leukocytes in patients with schizophrenia and evaluated the possible association of CR1 C5507G functional polymorphism with this disorder. In addition, in the blood of schizophrenia affected subjects the levels of circulating immune complexes (CIC) containing natural ligands of CR1, namely C1q and fragments of C3, were also determined. A control group included healthy subjects without family history of schizophrenia.

\section{Results}

\section{CR1 expression on blood cells}

The expression of CR1 on blood cells was quantified by flow cytometry. The results obtained are shown on Figure 1 and in table 1 . According to the data obtained,

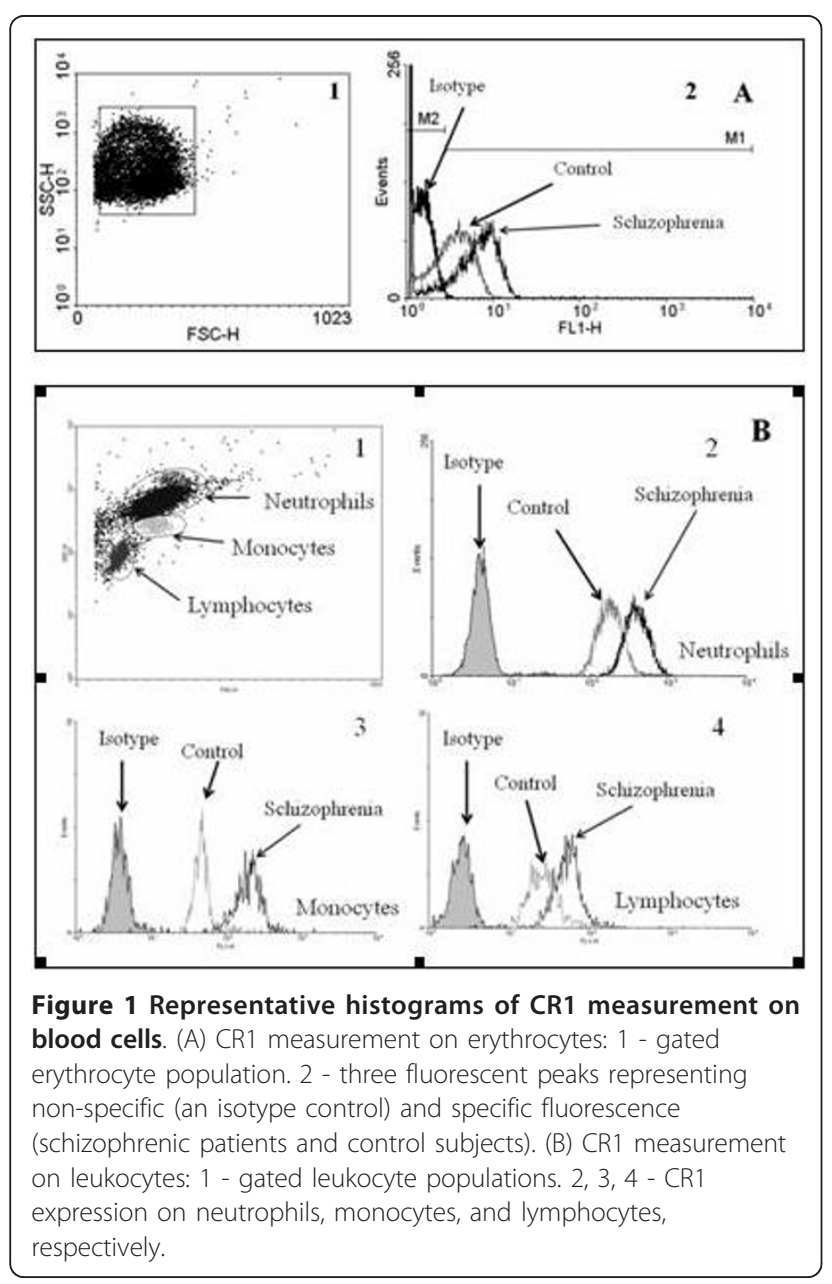

Table 1 CR1 expression on blood cells in schizophrenic patients and controls.

\begin{tabular}{cccc}
\hline Type of blood cells & \multicolumn{2}{c}{ CR1 expression, RFI } & $\boldsymbol{p}$ \\
\hline & Patients & Controls & \\
\hline Erythrocytes & $6.85[0.89]$ & $6.21[0.67]$ & 0.001 \\
\hline Lymphocytes & $22.35[8.35]$ & $19.30[7.90]$ & 0.011 \\
\hline Monocytes & $85.55[46.35]$ & $47.30[10.00]$ & $1.20 \mathrm{E}-08$ \\
\hline Neutrophils & $185.5[80.00]$ & $140.00[44.5]$ & 0.003 \\
\hline
\end{tabular}

CR1 expression levels for erythrocytes were significantly higher in patients compared to controls and were positively correlated with the duration of schizophrenia (rho $=0.637, p=0.004)$. The same applies to the percentage of CR1-positive E (patients: 83.84 [2.66] \% versus controls: 75.94 [6.74] \%, $p=7.48 \mathrm{E}-07$ ). Interestingly, the CR1 expression on subpopulation of leukocytes (L, monocytes $(\mathrm{M})$, and neutrophils $(\mathrm{N})$ ) in patients was significantly higher than in controls (table 1 ), whereas the percentage of CR1 positive L (patients: 11.69 [4.03] $\%$ versus controls: 17.26 [6.60] \%, $p=4.02 \mathrm{E}-05)$ and $\mathrm{M}$ (patients: 1.49 [0.91] \% versus controls: 5.19 [1.83] \%, $p$ $=1.42 \mathrm{E}-10)$ was significantly lower. No significant difference was observed in the number of positive $\mathrm{N}$ among studied groups (patients: 64.18 [12.15] \% versus controls: $59.93[9.60] \%, p=0.52)$. Also, there was no difference in CR1 expression between smokers and non-smokers in both groups.

The influence of CR1 C5507G polymorphism on CR1 expression on blood cells

Distribution of genotypes for CR1 C5507G SNP corresponded to the Hardy-Weinberg equilibrium. We found no significant differences in distribution of genotypes, allele and carriage frequencies, between the groups of schizophrenia patients and control subjects $(p>0.05$, table 2). The intergroup comparisons showed that in the $\mathrm{CC}$ genotype the levels of CR1 expression on $\mathrm{E}, \mathrm{M}$, and

Table 2 Distribution of CR1 C5507G genotypes and carriage rates for minor alleles in schizophrenic patients and controls.

\begin{tabular}{|c|c|c|c|c|}
\hline & & \multicolumn{2}{|c|}{$\begin{array}{c}\text { Frequency, } \\
\text { absolute (relative) }\end{array}$} & \multirow[t]{2}{*}{$\mathrm{OR}, \mathrm{Cl}, p$} \\
\hline & & Patients & Controls & \\
\hline & CC & $75(0.64)$ & $84(0.59)$ & \\
\hline \multirow[t]{2}{*}{ Genotype } & CG & $38(0.32)$ & $55(0.39)$ & \\
\hline & GG & $4(0.03)$ & $3(0.02)$ & $p=0.45$ \\
\hline \multirow[t]{2}{*}{ Allele } & $C$ & $188(0.80)$ & $223(0.79)$ & \\
\hline & G & $46(0.20)$ & $61(0.21)$ & $\mathrm{OR}=1.15, \mathrm{Cl}: 0.85-1.36, p=0.53$ \\
\hline \multirow[t]{2}{*}{ Carriage } & $C$ & $113(0.98)$ & $139(0.97)$ & \\
\hline & G & $42(0.41)$ & $58(0.36)$ & $\mathrm{OR}=0.78, \mathrm{Cl}: 0.66-1.16, p=0.63$ \\
\hline
\end{tabular}


$\mathrm{N}$ were higher in patients than in controls $(p<0.006)$, whereas in lymphocytes practically equal levels of CR1 expression in both groups were detected $(p>0.05)$. Further, we compared the levels of CR1 expression on the blood cells of normal allele homozygotes and mutant allele carriers $(\mathrm{CG}+\mathrm{GG})$ in patients and controls. Both groups showed increased CR1 expression on $E$ in $\mathrm{CC}$ homozygous subjects compared to mutant allele carriers (Figure 2), whereas levels of CR1 expression on L, $\mathrm{M}$, and $\mathrm{N}$ did not differ between these genotypes $(p>$ 0.05; table 3). No correlation between the CR1 5507G carriers and clinical characteristics of patients with schizophrenia as well as smokers and non-smokers in both study groups has been observed. In patients, the fractions of CR1 positive L (CC: 10.45 [5.41] \%, CG+GG: $13.51[4.90] \%, p=0.047)$ and $\mathrm{N}(\mathrm{CC}: 62.95[10.90] \%$, CG+GG: 70.75 [14.98] \%, $p=0.026)$ were higher in mutant allele carriers, whereas in control subjects the number of CR1 positive $E$ were significantly higher in CC homozygotes (CC: 80.10 [4.54] \%, CG+GG: 75.09 [6.48] \%, $p=0.023)$.

\section{Levels of $\mathrm{C} 1 \mathrm{q}-\mathrm{ClC}$ and $\mathrm{C} 3 \mathrm{~d}-\mathrm{CIC}$ in the blood}

The median level of C1q-CIC in the blood serum was significantly higher in patients compared to controls (patients 27.25 [4.17] ug/mL versus controls: 24.23 [3.88] ug/mL, $p=0.017$ ), whereas the levels of C3d-CIC were practically the same in both groups (patients: 14.20 [2.68] $\mathrm{ug} / \mathrm{mL}$ versus controls14.09 [3.77] $\mathrm{ug} / \mathrm{mL}, p=$ 0.66). No difference in C3d-CIC and C1q-CIC levels was observed between CR1 5507 CC homozygotes and mutant allele carriers in patients $(p>0.05)$. In contrast, the $\mathrm{G}$ allele carriers in control subjects had significantly elevated C1q-CIC levels (CG+GG: 25.18 [3.16] ug/mL versus CC: 22.27 [3.73] ug/mL, $p=0.015)$. Correlation

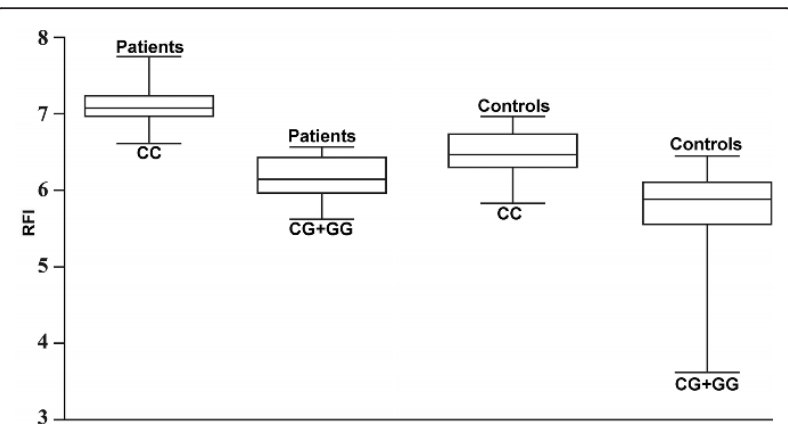

Figure 2 The intragroup comparison $(n=117$ patients, $n=142$ controls) of CR1 expression (RFI) with regard to the CR1 5507 standard allele homozygotes (CC) versus $\mathrm{G}$ mutant allele carriers (CG+GG). The data are expressed as whisker box plots; the box represents the 25-75th percentiles, the median is indicated by a bar across the box, the whiskers on each box represent the minimum and maximum level. $P=0.0003$ when comparing levels between patients and controls. analysis showed that CR1 expression levels on blood cells in control subjects positively correlated with C3dCIC levels (rho $=0.44, p=0.049$ ) and negatively correlated with $\mathrm{C} 1 \mathrm{q}-\mathrm{CIC}$ levels (rho $=-0.42, p=0.058$ ). In patients with schizophrenia, no significant correlation between these parameters was observed. Also, CIC levels did not differ between smokers and non-smokers among the patients and controls.

\section{Discussion}

Recent studies provide evidence of the involvement of the complement system alterations in schizophreniaassociated immune system abnormalities including autoimmunity and inflammation [13-17]. In this work, we have extended the current knowledge on the state of the complement system in schizophrenia by studying CR1 expression on blood cells, the levels of CIC bound to CR1 ligands, the products of the complement activation, and the CR1 C5507G functional polymorphism in diseased and healthy subjects.

The results obtained for the first time demonstrate an increased expression of CR1 on erythrocytes and subpopulations of leukocytes (L, M, and N), accompanied by the elevated number of CR1 positive $E$ and reduced number of CR1 positive $L$ and $M$ in patients with schizophrenia as compared to healthy subjects. Regarding CIC bound to complement-derived CR1 ligands, the increased levels of C1q-CIC in schizophrenia patients compared to healthy controls were detected, whereas no significant difference in the levels of C3d-CIC between patients and controls was observed.

Changes in CR1 expression on blood cells have been implicated in a variety of diseases (systemic lupus erythematosus, acute immunodeficiency syndrome, rheumatoid arthritis, malarial anaemia, insulin-dependent diabetes, myocardial infarction, etc) associated with immune system dysfunction, development of inflammatory and autoimmune reactions [26,27,29-33]. Depending on the diseased condition, these changes may be determined by either genetic or environmental factors. The present finding of the increased CR1 expression levels on blood cells of schizophrenia patients may be a consequence of the elevated levels of the total population of IC in circulation reported by us previously [34], as well as increased levels of $\mathrm{C1q}$-CIC reported in the present work. As noted in the introduction, binding of erythrocyte CR1 to the complement component C1q attached to IC serves to mediate clearance of IC [5]. In addition, increase of CR1 expression on leukocytes can be induced by tumor necrosis factor- $\alpha$ and interleukin- 1 $[35,36]$, which are elevated in the blood of schizophrenic patients [37].

We also observed an enhanced number of CR1 positive $\mathrm{E}$ in schizophrenia patients, while fractions of CR1 
Table 3 Comparison of CR1 expression on blood cells of schizophrenic patients and healthy controls depending on the CR1 C5507G genotypes.

\begin{tabular}{ccccccc}
\hline & \multicolumn{3}{c}{ CR1 expression in patients } & \multicolumn{3}{c}{ CR1 expression in controls } \\
\hline Type of blood cells & CC & CG+GG & $\boldsymbol{p}$ & CC & CG+GG & $\boldsymbol{p}$ \\
\hline Erythrocytes & $7.07[0.31]$ & $6.15[0.52]$ & $6.57 \mathrm{E}-08$ & $6.46[0.46]$ & $5.87[0.52]$ & $6.88 \mathrm{E}-06$ \\
\hline Lymphocytes & $21.70[8.48]$ & $24.15[9.33]$ & $>0.05$ & $19.5[8.25]$ & $18.50[8.50]$ & $>0.05$ \\
\hline Monocytes & $80.80[49.35]$ & $89.60[45.88]$ & $>0.05$ & $48.86[9.00]$ & $45.45[16.75]$ & $>0.05$ \\
\hline Neutrophils & $190.00[91.30]$ & $174.50[65.00]$ & $>0.05$ & $128.00[42.50]$ & $149.5[97.00]$ & $>0.05$ \\
\hline
\end{tabular}

positive $\mathrm{L}$ and $\mathrm{M}$ were significantly decreased compared to control subjects. Increased number of CR1 positive $\mathrm{E}$ in circulation might be related to the enhanced hematopoiesis in response to cytokines and other inflammatory agents [38], while reduced number of CR1 positive leukocyte subpopulations might be explained by increased rate of apoptosis induced by antipsychotic treatment [39-41].

Distributions of the allele and genotype frequencies of the CR1 C5507G SNP in schizophrenia patients do not differ from healthy subjects. Therefore, despite the important role of the complement system in the pathogenesis of schizophrenia [15-22], its type 1 receptor gene $\mathrm{C} 5507 \mathrm{G}$ polymorphism does not contribute to the genetic susceptibility to this disease. Further, we compared the levels of CR1 expression on the blood cells of normal allele homozygotes and mutant allele carriers $(\mathrm{CG}+\mathrm{GG})$ in patients and controls. Both groups showed increased CR1 expression on E in CC homozygous subjects compared to mutant allele carriers (Figure 2), whereas levels of CR1 expression on L, M, and L did not differ between these genotypes $(p>0.05$, table 3$)$. Interestingly, Wilson et al. found the association of genomic polymorphism with a cis-acting regulatory element for the expression of CR1 on E [42].

\section{Conclusions}

In conclusion, on the basis of our results we suggested that schizophrenia is associated with the increased expression of CR1 on E, L, M, and $\mathrm{N}$ accompanied by the elevated number of CR1 positive E, reduced number of CR1 positive $\mathrm{L}$ and $\mathrm{M}$, and increased level of C1qCIC. Interestingly, the levels of CR1 expression on $\mathrm{E}$ were higher in CR1 5507 CC homozygotes when compared to those in $G$ allele carriers both among the patients with schizophrenia and control subjects. Further studies in other ethnic groups and populations are needed to confirm our findings.

\section{Limitations of our study}

Some limitations in this study should be noted. Firstly, we analyzed a relatively small sample size (117 schizophrenia patients and 142 healthy subjects). Secondly, all the patients with schizophrenia involved in the present study were receiving antipsychotic treatment.

\section{Methods}

\section{Study population}

In total, 117 patients with paranoid schizophrenia (F20.0) and 142 healthy subjects were enrolled in the study. All subjects were unrelated Armenians living in Armenia. All patients were diagnosed according to the ICD-10 criteria [43] by two independent experienced psychiatrists. The affected subjects (females/males: 60/57, mean age \pm SD: $45 \pm 10$ years, age at the first-onset of illness: mean \pm SD: $23 \pm 9$ years, duration of illness mean \pm SD: $19 \pm 7$ years, smokers/non-smokers: 33/84) were recruited from the clinics of the Psychiatric Medical Center of the Ministry of Health of the Republic of Armenia (MH RA). All patients were receiving typical antipsychotic haloperidol and phenazepamum during their treatment. Healthy volunteers (females/males: 70/72, mean age \pm SD: $42 \pm$ 12 years, smokers/non-smokers: 50/72) were recruited from the Erebouni Medical Center MH RA and served as a reference control population. They passed a special examination by two independent experienced psychiatrists proved no personal or family history of mental disorders. All subjects gave their informed consents to provide $10 \mathrm{ml}$ of venous blood for the purposes of this study. The study was approved by the Ethical Committee of the Institute of Molecular Biology of the National Academy of Sciences (NAS) RA.

\section{Collection of blood samples}

Ten $\mathrm{mL}$ of morning fasting venous blood was collected from each patient and healthy subject using EDTA as anticoagulant.

\section{Genomic DNA extraction from the whole blood}

Genomic DNA samples were isolated from fresh blood by the standard phenol-chloroform procedure [44] and stored at $-30^{\circ} \mathrm{C}$ until further use.

\section{Genotyping analysis of CR1 C5507G polymorphism}

All DNA samples were genotyped for CR1 C5507G polymorphism using polymerase chain reaction with 
sequence specific primers (PCR-SSP) under the conditions described elsewhere [45]. The primer sequences were:

allele C, forward: 5'ATCCGCTGCACAAGTGACCC; allele G, forward: 5'ATCCGCTGCACAAGTGACCG; constant reverse: 5'CCCTACTAAATCTGGACCTC ATC.

The presence/absence of allele-specific amplicons was visualized by electrophoresis on $2 \%$ agarose gel and ethidium bromide fluorescence in reference to a molecular weight marker.

\section{Isolation of erythrocytes and blood plasma from the whole blood}

Blood samples were centrifuged $(700 \mathrm{~g} \times 10 \mathrm{~min})$ at room temperature. After centrifugation plasma was separated and a buffy coat was removed. A pellet of $\mathrm{E}$ was washed 3 times by resuspension in BD CellWASH ${ }^{\mathrm{TM}}$ solution (BD Biosciences, CA, USA) followed by centrifugation $(700 \mathrm{~g} \times 10 \mathrm{~min})$ at $4^{\circ} \mathrm{C}$. After washing the $\mathrm{E}$ resuspended in the same solution were counted and adjusted to a final concentration of $10^{6}$ cells $/ \mathrm{mL}$.

\section{Isolation of leukocytes from the whole blood}

Blood samples were treated with BD lysis solution (BD Biosciences, CA, USA) to lyse E, and then centrifuged $(700 \mathrm{~g} \times 10 \mathrm{~min})$ at room temperature. A pellet, containing leukocytes, was washed 3 times by resuspension in BD CellWASH ${ }^{\mathrm{TM}}$ solution followed by centrifugation $(700 \mathrm{~g} \times 10 \mathrm{~min})$ at room temperature. After washing the leukocytes were resuspended in the same solution, counted and adjusted to a final concentration of $10^{6}$ cells $/ \mathrm{mL}$.

\section{Measurement of CR1 expression on blood cells}

Suspensions of E and L (100 uL of each) were incubated with FITC-labeled anti-CD35 monoclonal antibody (catalog number 555452, BD Pharmingen, USA) for 1.5-2 hours and then fluorescence at $518 \mathrm{~nm}$ (excitation 488 $\mathrm{nm}$ ) was measured on BD FACScan flow cytometer supplied with BD CellQuest ${ }^{\mathrm{TM}}$ Pro 5.2 software (BD Bioscience, USA). Histogram overlays and dot plots were produced by WinMDI 2.9 software package. Representative pictures of gated cell populations and histograms are shown on Figure 1. A matching isotype control (mouse IgG1 isotype control FITC, catalog number 11-4714-42, eBioscience, USA) was used to measure non-specific binding of antibodies to studied cells, and this value indicated in each histogram with a filled curve was subtracted from the raw data. E and subpopulations of leukocytes ( $\mathrm{L}, \mathrm{M}$, and $\mathrm{N}$ ) were identified by forward versus side scatter parameters, and surface expression of CR1 in each cell population was quantified. An isotype control was used to estimate the fraction of CR1 positive cells (see Figure 1) which was expressed as a percentage of positive cells among the cells of particular population. Surface expression is given in relative fluorescence intensity units (RFI) as median [interquartile range]. Events with RFI exceeding those of isotype control were considered as CR1-positive, and were gated on the histogram as a separate subpopulation. The median RFI was measured to determine CR1 expression in the marked subpopulation. Histogram overlays and dot plots were produced by WinMDI 2.9 software package.

\section{Measurement of $\mathrm{C} 1 \mathrm{q}$ - and $\mathrm{C} 3 \mathrm{~d}$-bound $\mathrm{CIC}$}

The levels of C3d-and C1q-bound CIC (C3d-CIC and $\mathrm{C} 1 \mathrm{q}-\mathrm{CIC}$, respectively) were measured in plasma by enzyme-linked immunosorbent assay (ELISA) using commercially available kits (IMTEC-C3d-CIC and IMTEC-C1q-CIC, Human GmBH, Germany) according to manufacturer's instructions. The level of C3d-CIC reflects total concentration of $\mathrm{CIC}$ with bound $\mathrm{C} 3$ fragments (C3b, iC3b, and $\mathrm{C} 3 \mathrm{dg}$ ), which contain the fragment of the $\mathrm{C} 3$ alpha polypeptide chain known as the "d" fragment.

\section{Statistical analysis}

The distributions of genotypes for CR1 C5507G were checked for correspondence to Hardy-Weinberg (H-W) equilibrium. In order to find potential relevance of the selected CR1 SNP to schizophrenia, its allele (gene) and phenotype frequencies (carriage rates) in patients and control subjects were compared. The significance of differences between allele and phenotype frequencies calculated on the base of the number of observed genotypes was determined using Pearson's Chi-square test. The odds ratio (OR), 95\% confidence interval (CI), and Pearson's $p$-value were calculated. The Mann-Whitney $U$ test was used for evaluation of intergroup differences in the levels of CR1 expression, C1q-CIC, and C3d-CIC and percentage of CR1 positive cells. Survival analysis was performed to evaluate the possible association between clinical/demographic characteristics of schizophrenia patients and genotypes and expression levels observed.

Group statistics, otherwise indicated, was presented as median [interquartile range]. Spearman's rank correlation coefficient (rho) was calculated to assess relationships between measured parameters. $P$-values less than 0.05 were considered significant. Statistical analysis was performed using "Graphpad Prism" (GraphPad Software Inc., USA) software.

\section{List of abbreviations}

CR1: complement receptor type 1; C1q: q subcomponent of complement component 1; C3b: iC3b and C3dg, fragments of complement component 3; C4b: opsonic fragment of C4; FITC: fluorescein isothiocyanate; RFI: relative 
fluorescence intensity; PCR-SSP: polymerase chain reaction with sequence specific primers; SNP: single nucleotide polymorphism; ELISA: enzyme-linked immunosorbent assay; E: erythrocyte; L: Iymphocyte; M: monocyte; N: neutrophil; CIC: circulating immune complexes; OR: odds ratio; $\mathrm{Cl}$ : confidence interval; ICD-10: International classification of diseases, 10th edition.

\section{Acknowledgements}

The authors express their gratitude to the administration and medical staff of the clinics of Psychiatric Medical Center and Erebouni Medical Center $\mathrm{MH}$ RA, performing diagnostics of the patients, examination of healthy subjects involved in this study and blood sampling. This study was supported by the grant (RZ: \# ECSP-09-70) of the State Committee of Science of the Ministry of Education and Science of RA and the National Foundation of Science and Advanced Technologies (RA) and Czech Ministry of Education (MSM6198959205), IGA UP project no. LF_2010_008, Czech Republic. Infrastructural part of this research (Institute of Molecular andTranslational Medicine) was supported from the Operational programme"Research and Development for Innovations (project CZ.1.05/2.1.00/01.0030).

\section{Author details}

${ }^{1}$ Institute of Molecular Biology, National Academy of Sciences of the Republic of Armenia, 7 Hasratyan St., 0014, Yerevan, Armenia. ${ }^{2}$ Faculty of Medicine and Dentistry, Palacky University, 6 I. P. Pavlova St., 775 20, Olomouc, Czech Republic. ${ }^{3}$ Biological Faculty of Yerevan State University, 1 Al. Manoogian St., 0025, Yerevan, Armenia.

\section{Authors' contributions}

AA isolated blood cells and drafted the manuscript. RZ performed DNA isolation from blood samples and genotyping analysis. AK measured CIC levels in patients with schizophrenia and healthy subjects. DP performed flow cytometry experiments while RA interpreted the data obtained. FM designed primers for PCR-SSP and did statistical analysis. MP performed genotyping study design and accompanied with $A B$, who generated the idea of the study, developed the final version of manuscript. All authors read and approved the final manuscript.

\section{Competing interests}

The authors declare that they have no competing interests.

Received: 7 June 2011 Accepted: 25 August 2011

Published: 25 August 2011

\section{References}

1. Fearon DT: Identifcation of the membrane glycoprotein that is the $\mathrm{C} 3 \mathrm{~b}$ receptor of the human erythrocyte, polymorphonuclear leukocyte, B lymphocyte, and monocyte. J Exp Med 1980, 152:20-30.

2. Liu D, Niu ZX: The structure, genetic polymorphisms, expression and biological functions of complement receptor type 1 (CR1/CD35). Immunopharmacol Immunotoxicol 2009, 31:524-535.

3. Schifferli JA, Ng YC, Peters DK: The role of complement and its receptor in the elimination of immune complexes. N Eng / J Med 1986, 315:488-495.

4. Hess C, Schifferli JA: Immune adherence revisited: novel players in an old game. News Physiol Sci 2003, 18:104-108.

5. Klickstein LB, Barbashov SF, Liu T, Jack RM, Nicholson-Weller A: Complement receptor type 1 (CR1, CD35) is a receptor for C1q. Immunity 1997, 7:345-355

6. Eggleton P, Tenner AJ, Reid KB: C1q receptors. Clin Exp Immunol 2000, 120:406-412.

7. McGreal E, Gasque P: Structure-function studies of the receptors for complement C1q. Biochem Soc Trans 2002, 30:1010-1014.

8. Ghiran I, Tyagi SR, Klickstein LB, Nicholson-Weller A: Expression and function of $\mathrm{C} 1 \mathrm{q}$ receptors and $\mathrm{C} 1 \mathrm{q}$ binding proteins at the cell surface. Immunobiology 2002, 205:407-420.

9. Ghiran I, Barbashov SF, Klickstein LB, Tas SW, Jenseius JC, NicholsonWeller A: Complement receptor $1 / C D 35$ is a receptor for mannanbinding lectin. J Exp Med 2000, 192:1797-1808.

10. Krych-Goldberg M, Atkinson JP: Structure-function relationships of complement receptor type 1. Immunol Rev 2001, 180:112-122.
11. Hebert LA: The clearance of immune complexes from the circulation of man and other primates. Am J Kidney Dis 1991, 17:352-361.

12. Thornton BP, Vetvicka $V$, Ross GD: Natural antibody and complementmediated antigen processing by B lymphocytes. J Immunol 1994, 152:1727-1737.

13. Bacle F, Haeffner-Cavaillon N, Laude M, Couturier C, Kazatchkine MD: Induction of IL-1 release through stimulation of the $\mathrm{C} 3 \mathrm{~b} / \mathrm{C} 4 \mathrm{~b}$ complement receptor type one (CR1, CD35) on human monocytes. J Immunol 1990, 144:147-152.

14. Rochowiak A, Niemir Zl: The role of CR1 complement receptor in pathology. Pol Merkur Lekarki 2010, 28:84-88.

15. Hanson DR, Gottesman II: Theories of schizophrenia: a geneticinflammatory-vascular synthesis. BMC Med Genet 2005, 6:7.

16. Yum SY, Yum SK, Kim T, Hwang MY: Clinical perspectives on autoimmune processes in schizophrenia. Psychiatr Clin North Am 2009, 32:795-808.

17. Monji A, Kato T, Kanba S: Cytokines and schizophrenia: Microglia hypothesis of schizophrenia. Psychiatry Clin Neurosci 2009, 63:257-265.

18. Hakobyan S, Boyajyan A, Sim RB: Classical pathway complement activity in schizophrenia. Neurosci Lett 2005, 374:35-37.

19. Mayilyan KR, Arnold JN, Presanis JS, Soghoyan AF, Sim RB: Increased complement classical and mannan-binding lectin pathway activities in schizophrenia. Neurosci Lett 2006, 404:336-341.

20. Mayilyan KR, Dodds AW, Boyajyan AS, Soghoyan AF, Sim RB: Complement C4B protein in schizophrenia. World J Biol Psychiatry 2008, 9:225-230.

21. Mayilyan KR, Weinberger DR, Sim RB: The complement system in schizophrenia. Drug News Perspect 2008, 21:200-210.

22. Boyajyan A, Khoyetsyan A, Chavushyan A: Alternative complement pathway in schizophrenia. Neurochem Res 2010, 35:894-898.

23. Mah S, Nelson MR, Delisi LE, Reneland RH, Markward N, James MR, Nyholt DR, Hayward N, Handoko H, Mowry B, Kammerer S, Braun A: Identification of the semaphorin receptor PLXNA2 as a candidate for susceptibility to schizophrenia. Mol Psychiatry 2006, 11:471-478.

24. Zorzetto M, Ferrarotti I, Trisolini R, Lazzari Agli L, Scabini R, Novo M, De Silvestri A, Patelli M, Martinetti M, Cuccia M, Poletti V, Pozzi E, Luisetti M: Complement receptor 1 gene polymorphisms are associated with idiopathic pulmonary fibrosis. Am J Respir Crit Care Med 2003, 168:330-334.

25. Katyal M, Tiwari SC, Kumar A, Dinda AK, Arora V, Kumar R, Das N: Association of complement receptor 1 (CR1, CD35, C3b/C4b receptor) density polymorphism with glomerulonephritis in Indian subjects. $\mathrm{Mol}$ Immunol 2004, 40:1325-1332.

26. Hepburn AL, Mason JC, Davies KA: Expression of Fcgamma and complement receptors on peripheral blood monocytes in systemic lupus erythematosus and rheumatoid arthritis. Rheumatology (Oxford) 2004, 43:547-554.

27. Erdei A, Isaák A, Török K, Sándor N, Kremlitzka M, Prechl J, Bajtay Z: Expression and role of CR1 and CR2 on $B$ and $T$ lymphocytes under physiological and autoimmune conditions. Mol Immunol 2009, 46:2767-2773.

28. Khera R, Das N: Complement Receptor 1: Disease associations and therapeutic implications. Mol Immunol 2009, 46:761-772.

29. Kazatchkine MD, Jouvin MH, Wilson JG, Fischer E, Fischer A: Human diseases associated with C3 receptor deficiencies. Immunol Lett 1987, 14:191-195.

30. Ruuska PE, Ikäheimo I, Silvennoinen-Kassinen S, Käär ML, Tiilikainen A: Normal C3b receptor (CR1) genomic polymorphism in patients with insulin-dependent diabetes mellitus (IDDM): is the low erythrocyte CR1 expression an acquired phenomenon? Clin Exp Immunol 1992, 89:18-21.

31. Waitumbi JN, Opollo MO, Muga RO, Misore AO, Stoute JA: Red cell surface changes and erythrophagocytosis in children with severe plasmodium falciparum anemia. Blood 2000, 95:1481-1486.

32. Serebruany $V L$, Atar $D$, Murugesan $S R$, Jerome $S$, Semaan $H$, Gurbel PA: Effect of coronary thrombolysis on the plasma concentration of osteonectin (SPARC, BM40) in patients with acute myocardial infarction. J Thromb Thrombolysis 2000, 10:197-202.

33. MCCarthy D, Taylor MJ, Bernhagen J, Perry JD, Hamblin AS: Leukocyte integrin and CR1 expression on peripheral blood leucocytes of patients with rheumatoid arthritis. Ann Rheum Dis 1992, 51:307-312.

34. Hakobyan S, Avetisyan G, Boyajyan A, Torosyan S, Khachatryan G, Tatevosyan S: Circulating immune complexes in blood of patients with positive family history of schizophrenia. Dokl Biochem Biophys 2001, 380:343-344. 
35. Berger $\mathrm{M}$, Wetzler $\mathrm{EM}$, Wallis RS: Tumor necrosis factor is the major monocyte product that increases complement receptor expression on mature human neutrophils. Blood 1988, 71:151-158.

36. Ogle JD, Noel JG, Sramkoski RM, Ogle CK, Alexander JW: The effects of cytokines, platelet activating factor, and arachidonate metabolites on C3b receptor (CR1, CD35) expression and phagocytosis by neutrophils. Cytokine 1990, 2:447-455.

37. Theodoropoulou S, Spanakos G, Baxevanis CN, Economou M, Gritzapis AD, Papamichail MP, Stefanis CN: Cytokine serum levels, autologous mixed lymphocyte reaction and surface marker analysis in never medicated and chronically medicated schizophrenic patients. Schizophr Res 2001, 47:13-25.

38. Mardi T, Toker S, Melamed S, Shirom A, Zeltser D, Shapira I, Berliner S, Rogowski O: Increased erythropoiesis and subclinical inflammation as part of the metabolic syndrome. Diabetes Res Clin Pract 2005, 69:249-255

39. Pillai A, Dhandapani KM, Pillai BA, Terry AV Jr, Mahadik SP: Erythropoietin prevents haloperidol treatment-induced neuronal apoptosis through regulation of BDNF. Neuropsychopharmacology 2008, 33:1942-1951.

40. Kim NR, Park SW, Lee JG, Kim YH: Protective effects of olanzapine and haloperidol on serum withdrawal-induced apoptosis in SH-SY5Y cells. Prog Neuropsychopharmacol Biol Psychiatry 2008, 32:633-642.

41. Williams DP, Pirmohamed M, Naisbitt DJ, Uetrecht JP, Park BK: Induction of metabolism-dependent and -independent neutrophil apoptosis by clozapine. Mol Pharmacol 2000, 58:207-216.

42. Wilson JG, Murphy EE, Wong WW, Klickstein LB, Weis JH, Fearon DT: Identification of a restriction fragment length polymorphism by a CR1 CDNA that correlates with the number of CR1 on erythrocytes. J Exp Med 1986, 164:50-59

43. The World Health Organization: The International Statistical Classification of Diseases and Related Health Problems. Geneva, 101992.

44. Sambrook J, Russell DW: Molecular Cloning: A Laboratory Manual. 3 edition. New York: Cold Spring Harbor Laboratory Press; 2001.

45. Bunce $M, O^{\prime}$ Neill $C M$, Barnardo MC, Krausa P, Browning MJ, Morris PJ, Welsh KI: Phototyping: comprehensive DNA typing for HLA-A, B, C, DRB3, DRB4, DRB5\&DQB1 by PCR with 144 primer mixes utilizing sequencespecific primers (PCR-SSP). Tissue Antigens 1995, 46:355-367.

\section{Pre-publication history}

The pre-publication history for this paper can be accessed here: http://www.biomedcentral.com/1472-6890/11/10/prepub

doi:10.1186/1472-6890-11-10

Cite this article as: Arakelyan et al:: Functional characterization of the complement receptor type 1 and its circulating ligands in patients with schizophrenia. BMC Clinical Pathology 2011 11:10

\section{Submit your next manuscript to BioMed Central and take full advantage of:}

- Convenient online submission

- Thorough peer review

- No space constraints or color figure charges

- Immediate publication on acceptance

- Inclusion in PubMed, CAS, Scopus and Google Scholar

- Research which is freely available for redistribution

Submit your manuscript at www.biomedcentral.com/submit 